\title{
Extension Without Malignant Changes in Oral Melanotic Macule: A Report of Two Cases and Review of the Literature
}

\author{
Maryam Jalili Sadrabad ${ }^{1}$, Shabnam Sohanian (iD) ${ }^{2,}$, , Mona Bazazzadeh ${ }^{3}$ and Mohammad Hosein \\ Amirzade-Iranaq ${ }^{4}$ \\ ${ }^{1}$ Oral Medicine Department, Dental School, Semnan University of Medical Science, Semnan, Iran \\ ${ }^{2}$ Oral and Maxillofacial Pathology Department, Dental School, Semnan University of Medical Science, Semnan, Iran \\ ${ }^{3}$ Oral Medicine Department, Dental School, Isfahan University of Medical Science, Isfahan, Iran \\ ${ }^{4}$ Researcher in Oral and Maxillofacial Surgery, Tehran, Iran \\ "Corresponding author: Department of Oral and Maxillofacial Pathology, Dental School of Semnan University of Medical science, 17 Shahrivar Blvd., Postal Code: 3518794431 , \\ Semnan, Iran. Tel: +98-9125572614, Email: shabnam.sohanian@gmail.com
}

Received 2019 January 30; Revised 2019 May 23; Accepted 2019 June 01.

\begin{abstract}
Introduction: Oral melanotic macule (OMM) is a benign discoloration of oral mucosa that is identified by an increase in melanin pigmentation. The diagnosis of OMM is critical because it may have a similarity to oral melanoma at early stages. Therefore, microscopic examination is necessary to confirm the accurate diagnosis of the OMM.

Case Presentation: We report two cases of discoloration in the oral cavity with asymmetry and border irregularity. After obtaining informed consent, we performed an excisional biopsy that showed the increase of melanin adjacent to the basal and parabasal layers of squamous epithelial cells, confirming the diagnosis of OMM.

Conclusions: Early melanoma can have a similar clinical appearance to OMM. Therefore, an excisional biopsy can be done and the diagnosis of OMM can be confirmed by microscopic examination.
\end{abstract}

Keywords: Melanotic Macule, Melanosis, Differential Diagnosis, Pigmentation, Histopathology

\section{Introduction}

Oral melanotic macule(OMM) is a well-demarcated flat lesion that may be black, brown, blue, or grey in color (1). This lesion is so-called labial melanotic macule because it is a benign oral pigmentation frequently observed on lips but can even be noted inside of the mouth, most commonly on the gingiva, buccal mucosa, and palate $(2,3)$. This lesion can present at any age and sex and in black persons, but is more frequent in the fifth decade and females $(1,3)$. There is no evidence of recurrence or malignant changes except for cases with proliferating melanotic cells (1).

Various factors have been proposed as etiologic factors, including developmental factors (appearing from birth or in early childhood), which is common in dark skin people, environmental stressors such as long-term exposure to sunlight, smoking, medication, and systemic conditions such as Addison's disease (4). These are the differential diagnosis of pigmented lesion consists of melanotic macule, melanocytic nevus, oral melanoacanthoma, smoker's melanosis, blue nevi, foreign bodies, drug-induced lesion, Addison's disease, Peutz-Jeghers syndrome, Albright syn- drome, and oral melanoma (4).

Histopathologically, the OMM is characterized by increases in the melanin pigmentation adjacent to the basal and parabasal of the squamous epithelial cells and lamina propria (3). The OMM generally is a benign lesion but may have a malignant transformation into oral melanoma. Here, we report two cases of OMM with clinical extension and horizontal growing but histologically benign.

\section{Case Presentation}

\subsection{Case 1}

A 24-year-old Caucasian woman was admitted to the Oral Medicine Department of Shahid Sadoqi Dental School, with a complaint of growth of labial nevus. The patient's past medical, dental, and social histories were noncontributory. The lesion existed from birth, starting to grow from 3 - 4 years ago, as noted by her family 5 - 6 months ago. Visual examination showed that the lesion was an OMM with the following features: asymmetry (A+), 
border irregularity $(\mathrm{B}+)$, color variation in nonhomogeneous brown $(\mathrm{C}+)$, the dimension of $0.5 \times 0.5 \mathrm{~cm}(\mathrm{D}-)$, without elevation (5), and located on the mucosal aspect of the lower lip's right side close to the wetting line.

After obtaining informed consent, we performed an excisional biopsy, showing parakeratinized acanthotic squamous epithelial cells with increased melanin in basal and parabasal layers and melanin incontinence in underlying connective tissue without any malignant changes under microscopic examination (Figure 1). After three months of follow-up, there was no evidence of recurrence.

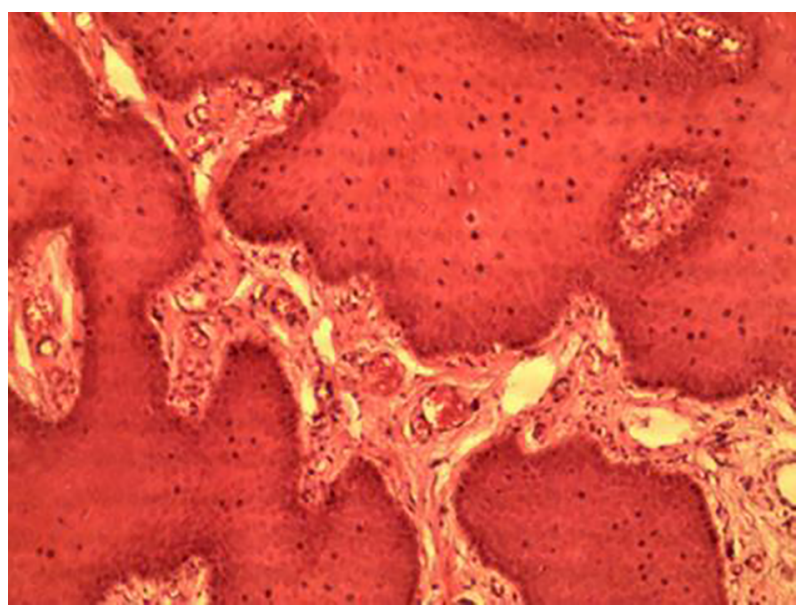

Figure 1. Microscopic feature showing parakeratinized acanthotic squamous epithelial cells with increased melanin in basal and parabasal layers $(\mathrm{H} \& \mathrm{E} \times 10)$

\subsection{Case 2}

Another 25-year-old Caucasian woman without any systemic disease came to the Oral Medicine Department of Shahid Sadoqi Dental School. The OMM was accidentally discovered during the routine intraoral examination. This lesion was located on the middle portion of the lower lip's wetting line with the following features: asymmetry $(\mathrm{A}+)$, border irregularity $(\mathrm{B}+)$, color variation in nonhomogeneous brown $(\mathrm{C}+)$, the dimension of $0.3 \times 0.2 \mathrm{~cm}(\mathrm{D}-)$, and without elevation (E-). The patient was asked about the duration of lesion existence. She claimed that she had it from birth but showed enlargement from 2 - 3 months ago. After obtaining informed consent, we performed the same treatment and biopsy results showed benign changes (Figure 2). After three months of follow-up, the patient showed no recurrence.

\section{Discussion}

OMM is a benign well-defined, small, dark pigmentation (6). Melanotic macule often occurs on the vermilion

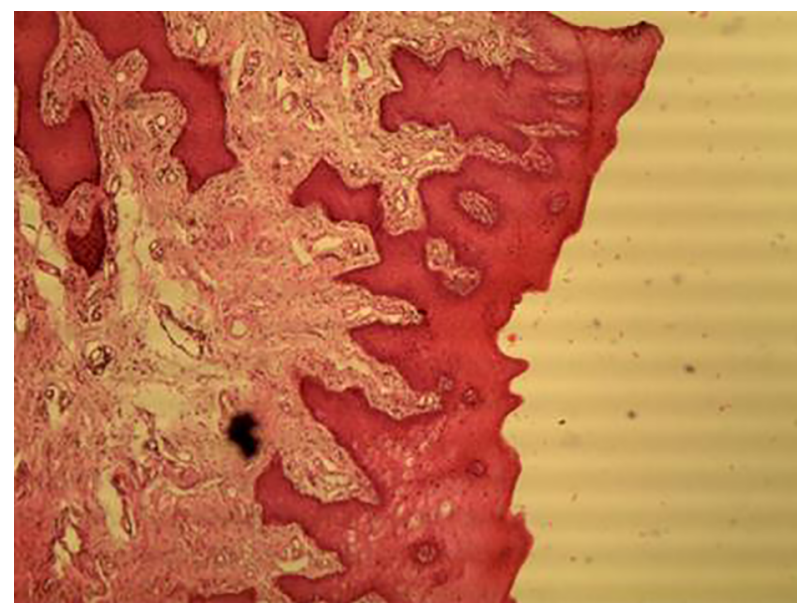

Figure 2. Histopathologic feature showing hyperplastic parakeratinized acanthoti epithelium

border of the lips and is called the labial melanotic macule. Intraorally, it may be noted more commonly on the gingiva, palatal, and buccal mucosa, referred to as OMM (3, 4).

Buchner and Hansen studied 105 cases of OMM and concluded that most patients developed an isolated lesion most commonly located on the vermilion border, followed by gingiva (7). The lesions are most frequently solitary and less than $1 \mathrm{~cm}$ but they can be multiple or larger in size (1, 4). George et al. reviewed 353 cases of OMM and found that the mean age at OMM incidence was 43.1 years with significant female predominance, most often on the lower lip, and more commonly in brown color with a mean size of $6.8 \mathrm{~mm}(8)$.

Numerous etiologic factors have been proposed, including physiologic factors, reactive factors, developmental factors, racial factors, Peutz-Jeghers syndrome, environmental stress, exposure to sunlight, trauma, smoking, medications such as antimalarial agents, hemochromatosis, systemic conditions such as Addison's disease and other endocrine disturbances, chronic pulmonary disease, and idiopathy. For the idiopathic lesions, the term "oral melanotic macule" has been suggested $(1,4)$.

Weathers et al. (9) and Page et al. (1) called pigmented lesions located on the labial vermilion as labial melanotic macule and oral melanotic macule if discoloration was inside the mouth. Localized melanocytic lesions of the oral mucosa consist of melanocytic nevus, melanocytic macule, atypical melanocytic hyperplasia, melanoacanthoma (MA), and melanoma. Melanotic macules are the best examples of such lesions, accounting for $86.1 \%$ of solitary melanocytic pigmented entities of the oral mucosa while 
oral melanocytic nevi and oral MA comprise $11.8 \%$ and $0.9 \%$, respectively. Oral melanoma and atypical hyperplasia of melanocytic cells are the least common, each comprising $0.6 \%$. OMM is mostly seen in patients with the mean age of 47.3 years, on the lower lip, with a female-to-male ratio of 2.1 (10). For oral melanoma, the patients are usually in the mean of 53.8-years-old; the common sites are palate and gingiva and there is no sex predilection $(5,10)$.

Other differential diagnoses of pigmented lesion of the mouth consist of smoker's melanosis, Addison's disease, blue nevi, Albright syndrome, foreign bodies, Peutz-Jeghers syndrome, drug-induced pigmentation, and Laugier-Hunziker syndrome (4).

The diagnosis of discolored entities of oral and perioral tissues is difficult. The pigmentation of the oral cavity can be divided into physiological/pathological and exogenous/endogenous categories (11). The family history, color, location, change in pattern, distribution (focal, multifocal, or diffuse), the duration of existence, and drug use can help make a differential diagnosis. Although some lesions can be definitely diagnosed on clinical assessment, a biopsy is usually required to reach a definitive diagnosis $(11,12)$.

Melanoma is a skin cancer that is very rare in the mouth. In the clinical feature, malignant melanoma of the oral cavity is mostly seen as an asymmetric, chromatic macule that increasingly grows and converts to the popular or nodular lesion later on. The radial phase signifies in-situ and superficial melanoma while the vertical phase denotes the nodular or invasive melanoma $(6,13)$.

Histopathologically, OMM is characterized by increased melanin in the basal cell layer (basal melanocytes) that is normal in number and does not have any cellular atypia; it may also exist in the melanophages of the upper part of the lamina propria (melanin incontinence) with the absence of elongated rete ridges $(6,14)$. These findings are in agreement with Sexton and Maize study (15).

If there was more pigmentation, rete ridges were elongated, and the quantity of normal-appearing melanocytes increased, a junctional nevus would be suggested (16). If there were proliferation and atypia of melanocytes, it would refer to atypical melanocytic hyperplasia, which can be related to early malignant melanoma (16).

The literature review supports that it is possible the primary oral melanoma (POM) is followed by a benign flat pigmented lesion by variable times (17-19). For a long time, OMM was considered an innocuous lesion without a potential of malignant changes until a few cases of transformation into the primary oral melanoma were described by Taylor and Lewis in 1990 (17), Kahn et al. in 2005 (18), and Kaehler et al. in 2008 (19). Oral pigmentation of the melanin is common but melanocytic hyperplasia is infrequent $(16,20)$. Kahn et al. stated that if epithelial hyper- plasia or dysplasia exists in the atypical melanocytic hyperplasia, it may represent a proliferative phase prior to overt malignant changes (17-19).

In recent cases, the histological evaluation was in agreement with common melanotic macule without any melanocyte hyperplasia and atypia, hence, clinically increasing in size. The treatment of OMM is controversial (4). Although the lesion is benign in nature with no recurrence tendency and malignant changes, it can be sometimes clinically indistinguishable from a nevus, in-situ malignant melanoma, primary melanoma, and other pigmented lesions (4). Thus, some investigators advocate the complete surgical excision of the suspected lesion and histological examination (20). Others propose frequent follow-ups with intervals and if any change is seen in size, shape, or color, the lesion must be removed, especially for lesions of high-risk location such as palate $(1,4,20)$.

Hegde et al. believe that, for melanotic lesions with an interval of fewer than 5 years with variations in size and shade or with bleeding and ulceration, the excision ought to be performed and lesions with no change in feature for five years or with an identified reason such as trauma can be periodically monitored. Nonetheless, in insufficient cases, a long follow-up is plausible $(1,4)$.

\subsection{Conclusions}

We conclude that although typical OMM is not premalignant, it can have a similar clinical appearance to oral melanoma at an early stage. Therefore, when OMM has clinical extension and irregularity, an excisional biopsy is necessary for histological confirmation of definitive diagnosis.

\section{Footnotes}

Conflict of Interests: There is no conflict of interest in this study.

Funding/Support: No Funding/Support was received.

\section{References}

1. Page LR, Corio RL, Crawford BE, Giansanti JS, Weathers DR. The oral melanotic macule. Oral Surg Oral Med Oral Pathol. 1977;44(2):219-26. doi: 10.1016/0030-4220(77)90272-9. [PubMed: 268573].

2. Glick M. Burket's oral medicine. 12th ed. PMPH USA; 2015.

3. Neville BW, Damm DD, Chi AC, Allen CM. Oral and maxillofacial pathology. Elsevier Health Sciences; 2015.

4. Pais S, Hegde SK, Bhat SS. Oral melanotic macule-a case report.JIndian Soc Pedod Prev Dent. 2004;22(2):73-5. [PubMed: 15491090].

5. Shen ZY, Liu W, Bao ZX, Zhou ZT, Wang LZ. Oral melanotic macule and primary oral malignant melanoma: Epidemiology, location involved, and clinical implications. Oral Surg Oral Med Oral Pathol Oral Radiol Endod. 2011;112(1):e21-5. doi: 10.1016/j.tripleo.2011.02.040. [PubMed: 21669356]. 
6. Carlos-Bregni R, Contreras E, Netto AC, Mosqueda-Taylor A, Vargas PA, Jorge J, et al. Oral melanoacanthoma and oral melanotic macule: A report of 8 cases, review of the literature, and immunohistochemical analysis. Med Oral Patol Oral Cir Bucal. 2007;12(5):E374-9. [PubMed: 17767102].

7. Buchner A, Hansen LS. Melanotic macule of the oral mucosa. A clinicopathologic study of 105 cases. Oral Surg Oral Med Oral Pathol.1979;48(3):244-9. doi:10.1016/0030-4220(79)90011-2. [PubMed: 289929].

8. Kaugars GE, Heise AP, Riley WT, Abbey LM, Svirsky JA. Oral melanotic macules. A review of 353 cases. Oral Surg Oral Med Oral Pathol. 1993;76(1):59-61. doi: 10.1016/0030-4220(93)90295-f. [PubMed: 8351123].

9. Weathers DR, Corio RL, Crawford BE, Giansanti JS, Page LR. The labial melanotic macule. Oral Surg Oral Med Oral Pathol. 1976;42(2):196-205. doi:10.1016/0030-4220(76)90124-9. [PubMed:1066601].

10. Buchner A, Merrell PW, Carpenter WM. Relative frequency of solitary melanocytic lesions of the oral mucosa. J Oral Pathol Med. 2004;33(9):550-7. doi: 10.1111/j.1600-0714.2004.00238.x. [PubMed: 15357676].

11. Gondak RO, da Silva-Jorge R, Jorge J, Lopes MA, Vargas PA. Oral pigmented lesions: Clinicopathologic features and review of the literature. Med Oral Patol Oral Cir Bucal. 2012;17(6):e919-24. doi: 10.4317/medoral.17679. [PubMed: 22549672]. [PubMed Central: PMC3505710].

12. Maymone MBC, Greer RO, Kesecker J, Sahitya PC, Burdine LK, Cheng $\mathrm{AD}$, et al. Premalignant and malignant oral mucosal lesions: Clinical and pathological findings. J Am Acad Dermatol. 2019;81(1):59-71. doi: 10.1016/j.jaad.2018.09.060. [PubMed: 30447325].
13. Barker BF, Carpenter WM, Daniels TE, Kahn MA, Leider AS, LozadaNur F, et al. Oral mucosal melanomas: The WESTOP Banff workshop proceedings. Western Society of Teachers of Oral Pathology. Oral Surg Oral Med Oral Pathol Oral Radiol Endod. 1997;83(6):672-9. [PubMed: 9195622].

14. Ho KK, Dervan P, O'Loughlin S, Powell FC. Labial melanotic macule: A clinical, histopathologic, and ultrastructural study. J Am Acad Dermatol. 1993;28(1):33-9. doi: 10.1016/0190-9622(93)70005-e. [PubMed: 8425968].

15. Sexton FM, Maize JC. Melanotic macules and melanoacanthomas of the lip. A comparative study with census of the basal melanocyte population. Am J Dermatopathol. 1987;9(5):438-44. [PubMed: 3688369].

16. Bork K. Diseases of the oral mucosa and the lips. Saunders; 1996.

17. Taylor CO, Lewis JS. Histologically documented transformation of benign oral melanosis into malignant melanoma: A case report. J Oral Maxillofac Surg. 1990;48(7):732-4. [PubMed: 2358951].

18. Kahn MA, Weathers DR, Hoffman JG. Transformation of a benign oral pigmentation to primary oral melanoma. Oral Surg Oral Med Oral Pathol Oral Radiol Endod. 2005;100(4):454-9. doi: 10.1016/j.tripleo.2005.01.018. [PubMed:16182166].

19. Kaehler KC, Russo PA, Egberts F, Warnke PH, Cerroni L, Hauschild A. Metastatic melanoma of the tongue arising from oral melanosis. Arch Dermatol.2008;144(4):558-60. doi:10.1001/archderm.144.4.558-b. [PubMed: 18427061].

20. Chaudhry AP, Hampel A, Gorlin RJ. Primary malignant melanoma of the oral cavity: A review of 105 cases. Cancer. 1958;11(5):923-8. doi: 10.1002/1097-0142(195809/10)11:5<923::aid-cncr2820110507>3.0.co;2-1. [PubMed: 13585343]. 